\title{
NUEVAS APORTACIONES AL DEBATE ESPECIALIZACIÓN- DIVERSIFICACIÓN EN EL SOLUTRENSE CANTÁBRICO. ESTUDIO ARQUEOZOOLÓGICO Y TAFONÓMICO DE LOS MACROMAMÍFEROS DE LA CUEVA DEL BUXU (CARDES, ASTURIAS, ESPAÑA)
}

\section{New contributions to debate specialization-diversification in the Cantabrian Solutrean. Archaeozoological and taphomic study of El Buxu Cave macromammals (Cardes, Asturias, Spain)}

\author{
Julio Antonio Rojo Hernández y Mario Menéndez Fernández ${ }^{1}$
}

Recibido el 14 de febrero de 2013. Aceptado el 28 de mayo de 2013

\begin{abstract}
Resumen. En este trabajo presentamos los datos tafonómicos y arqueozoológicos preliminares obtenidos en la revisión que hemos realizado, de los restos de macromamíferos que proporcionaron las excavaciones de la cueva del Buxu. Se cuantifica y evalúa la presencia de carnívoros así como su posible incidencia en la formación del registro arqueológico, también se ofrecen los datos de estacionalidad y edad estimada en el momento de la muerte de los macromamíferos, fundamentalmente de los principales taxones: Rupicapra rupicapra y Cervus elaphus. Los datos que aportamos podrán ser utilizados para que el debate sobre el tránsito a la diversificación de los recursos, observado a lo largo del Paleolítico superior, pueda ser efectuado con mayor precisión.
\end{abstract}

Palabras clave: Solutrense, especialización, diversificación, carnívoros, Rupicapra rupicapra.

Abstract. This paper presents the preliminary taphonomic and archaeozoological data obtained from the review of the remains of macromammals who provided the excavations of El Buxu cave. It quantifies and assesses the presence of carnivores and their potential impact on the formation of the archaeological record; also it offers the data for seasonality and estimated age at the time of the death of macromammals, mainly of the fundamental taxa: Rupicapra rupicapra and Cervus elaphus. The data could be used to debate about the transit to the observed diversification of resources, along the Upper Paleolithic, with accuracy.

Keywords: Solutrean, specialization, diversification, carnivore, Rupicapra rupicapra.

\section{INTRODUCCIÓN}

A los pies de un afloramiento calizo en el valle del Güeña, y con una visera que debió abrirse hacia el sur (Menéndez 1992), el yacimiento de la cueva del Buxu y su arte, se conocen desde principios del siglo pasado gracias a su publicación por parte de Obermaier y del Conde de la Vega del Sella en 1918, en la memoria número 20 de la Comisión de Investigaciones Paleontológicas y Prehistóricas (Menéndez 1992).

En contra de la opinión expresada por éstos, Breuil (1952) señala la existencia de niveles arqueológicos en el

(') Departamento de Prehistoria y Arqueologia. Facultad de Geografia e Historia. Universidad Nacional de Educación a Distancia. Ciudad Universitaria. Paseo Senda del Rey, 7.E-28040 Madrid (España)·mmenendez@geo.uned.es 
semicírculo que forma la zona de la entrada, y encuadra su arte parietal, en el Magdaleniense inferior y medio. En 1970 Olávarri (Menéndez 1984) efectúa sondeos en diversas zonas de la parte más cercana a la entrada de la cueva, constatando la existencia de materiales arqueológicos (Fig. 1).

El estudio y publicación de la industria lítica de estas excavaciones la efectuó Menéndez (1984), adscribiendo el yacimiento al Solutrense superior aunque con reservas por la escasez del utillaje. Las excavaciones en la cueva, fueron retomadas por Menéndez entre 1986 y 1989 (Fig. 1), constatándose, que una gran parte del yacimiento estaba arrasado. Estos trabajos sirvieron además, para clarificar la estratigrafía con mayor precisión, definir mejor las ocupaciones solutrenses, identificar una ocupación anterior, así como para documentar la presencia de alteraciones en alguna de las zonas escavadas (Menéndez 1992; 1999). El utillaje solutrense del Buxu, se compone de una típica punta de muesca en sílex proveniente del nivel 3 de la Zona A (Fig. 1 y Fig. 2), y otras piezas con claro retoque plano. Esta punta, es similar a las encontradas en el nivel 4 de La Riera (Straus 1986), o en el nivel 11c de Las Caldas (Corchón 1999). Las dataciones absolutas obtenidas, no sirvieron para clarificar la cronología pues son consideradas como contradictorias e incluso aberrantes; la más congruente, GrN-19386, nos da una fecha para el nivel 3 de $16730 \pm 500$ BP (Menéndez 1992).

De la macrofauna del yacimiento de la cueva del Buxu, objeto de esta comunicación, contamos con dos estudios. Soto (1984), publicó los resultados de su análisis sobre la fauna excavada en 1970 por Olávarri. Como era habitual en esas fechas, sus datos se centran en el número de especies en la que sobresale, como en el yacimiento de Amalda (Altuna 1990), el rebeco Rupicapra rupicapra. Se nos da también, el número de individuos por especie, dividido en dos grandes grupos de edad. Además y para obtener una valoración del aporte cárnico, se detalla el peso de los restos. Nada se nos dice en este estudio, de si se observaron marcas de carácter antrópico; tampoco otros datos de tipo tafonómico, como por ejemplo, las marcas producidas por procesos post-deposicionales o por carnívoros. De estos últimos, tan solo se enumeran las especies y el número total de los restos sin distinción taxonómica. Este, ha sido el trabajo utilizado en todos los estudios sintéticos sobre la fauna del Solutrense Final.

Los restos de fauna de las excavaciones dirigidas por Menéndez, fueron estudiados por el equipo de la Universidad Autónoma de Madrid, dirigido por Morales. Este trabajo permanece inédito y del mismo, tan sólo se conocen las referencias hechas por Menéndez (1999). En ellas, se indica la presencia de restos de ciervos, cabras y rebecos; esta circunstancia y la edad estimada en el momento de la muerte, le hacen pensar en una estrategia de "amplio espectro", con un perfil marcadamente atricional y una ocupación de carácter estacional. En este caso, se cita la presencia de marcas antrópicas en los restos, pero no, de si se han observado marcas producidas por otros agentes potencialmente acumuladores, como los carnívoros.

La falta de datos homogéneos en los estudios arqueozoológicos del Solutrense cantábrico, junto a los escasos estudios tafonómicos, alguno de ellos muy reciente (Mateos 1999; Yravedra 2004, 2010b; Yravedra y Gómez-Castanedo 2010; Yravedra et al. 2010), ha supuesto indudablemente un lastre para las conclusiones obtenidas en las obras de conjunto sobre el periodo y más concretamente, en el discurso de una progresiva especialización de los cazadores del $\mathrm{Pa}-$ leolítico superior. Los diferentes estudios de sintesis (Straus 1983; Altuna 1995; Quesada 1997; Yravedra 2002) han uti-

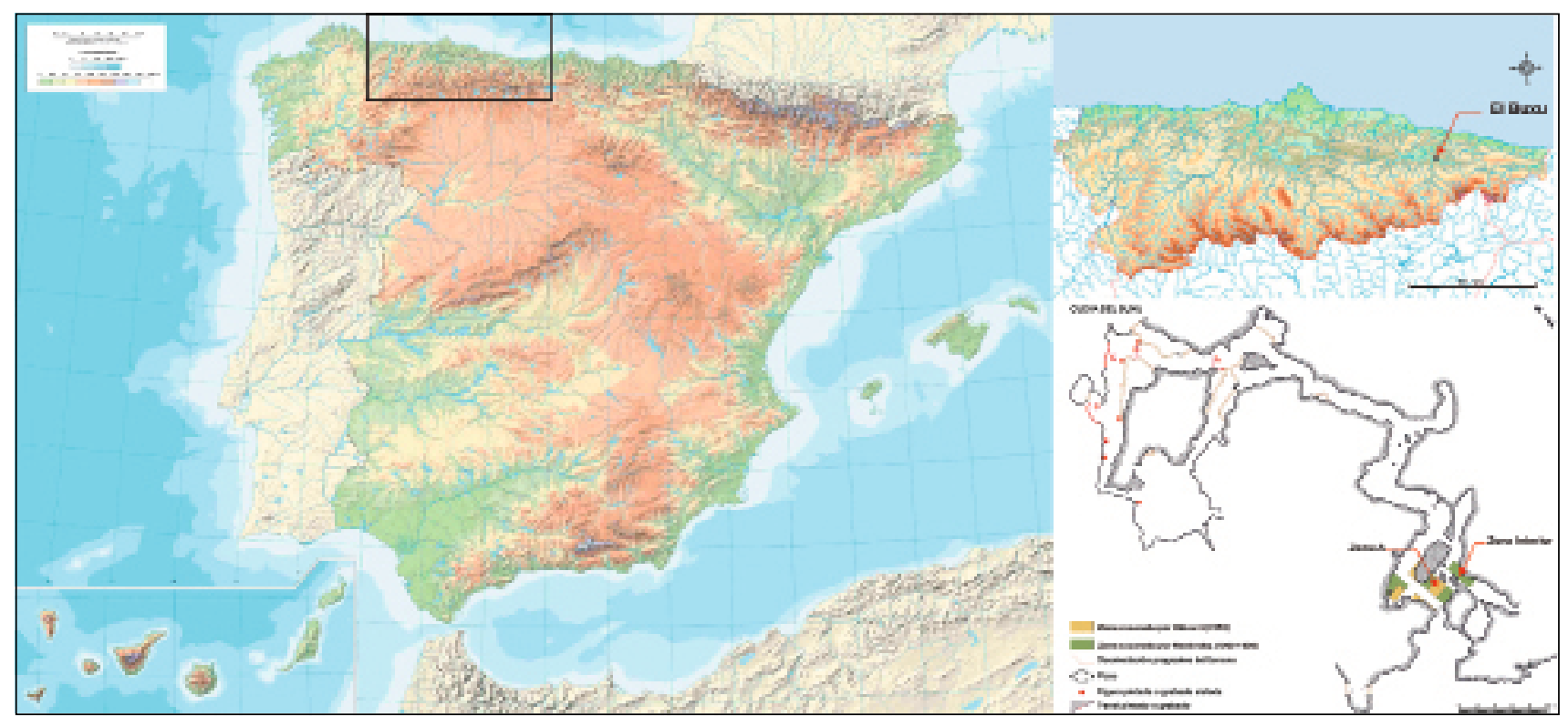

A Figura 1. Situación del yacimiento del Buxu y detalle de las zonas excavadas por Olávarri y por Menéndez. 


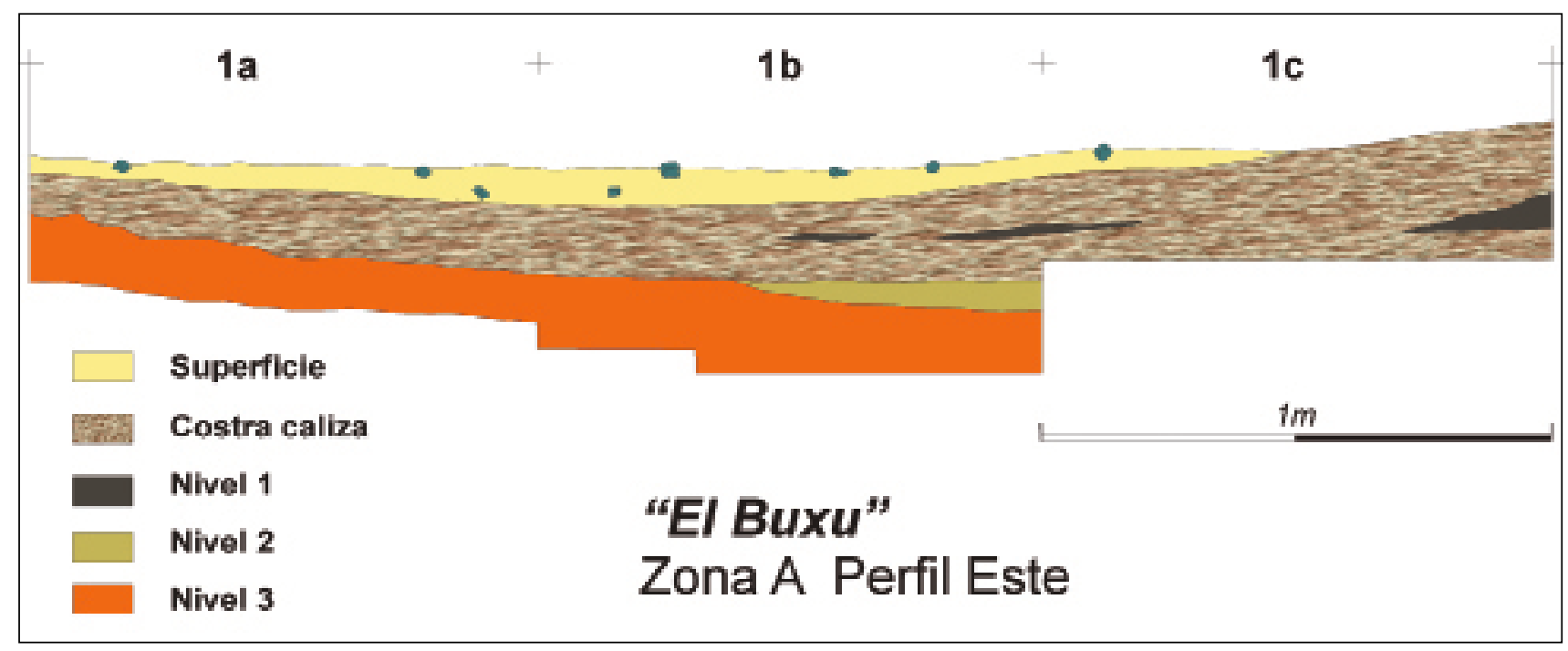

A Figura 2. Estratigrafía de la zona A de la cueva del Buxu.

lizado y comparado el número de individuos, el número de restos, incluso el índice de Simpson, para intentar determinar el grado de especialización o diversificación de los diferentes yacimientos cantábricos con estudios arqueozoológicos. En estos trabajos y con los datos publicados hasta este momento, El Buxu ha sido considerado como un yacimiento con caza moderadamente diversificada centrada en el rebeco, pero cercana a la diversificación (Quesada 1997) o no especializado con una taxón dominante, el rebeco, detectándose en conjunto, una especialización progresiva según avanza el Solutrense (Yravedra 2002). Hay que considerar asimismo que alguno de los yacimientos con restos de este periodo, como es el caso del nivel IV de Amalda, ha sido objeto de controversia sobre el causante de la acumulación (Altuna 1990; Altuna y Mariezkurrena 2010; Yravedra 2004, 2010a).

Parece necesario efectuar revisiones de las colecciones de fauna obtenidas en las excavaciones antiguas para, con criterios más actuales, obtener valoraciones fundamentalmente tafonómicas puesto que estas, pueden ayudar a determinar el agente acumulador de los restos y su grado de intervención.

\section{MATERIALES Y MÉTODOS}

El total de restos revisados supera los diecinueve mil, aunque los datos que presentamos, se refieren tan solo a los 10.269 incluidos en los niveles 1, 2 y 3, de las zonas A (excavada por Olávarri y por Menéndez) e Interior (excavada sólo por Menéndez), zonas que por proximidad comparten génesis estratigráfica (Fig. 1) y no parecen presentar alteraciones post-deposicionales. Aunque la superficie total excavada es mayor, los datos preliminares que aqui presentamos se refieren a los aproximadamente $6 \mathrm{~m}^{2}$ de las zonas especificadas anteriormente (Fig. 1). De los citados niveles, el que mayor número de restos aporta es el 3 (Fig. 2 y Tab. 1). La mayor parte de los restos se encuentran depositados en el Museo Arqueológico de Asturias en Oviedo.

\begin{tabular}{|l|r|r|}
\hline & \multicolumn{1}{|c|}{ N. $^{\circ}$ restos } & \multicolumn{1}{|c|}{$\%$} \\
\hline Nivel 1 & 1.465 & $14,30 \%$ \\
\hline Nivel 2 & 3.989 & $38,80 \%$ \\
\hline Nivel 3 & 4.815 & $46,90 \%$ \\
\hline Total & 10.269 & \\
\hline
\end{tabular}

A Tabla 1. Distribución de restos por niveles en las Zonas A e Interior de la cueva del Buxu.

Para el estudio de los restos se ha seguido la metodología propuesta por Yravedra (2006); las pequeñas modificaciones efectuadas, no afectan a los aspectos fundamentales de la misma. Se han efectuado por tanto, estudios taxonómicos, anatómicos y tafonómicos de todo tipo, evaluando y cuantificando las alteraciones de carácter antrópico, las producidas por procesos biológicos no antrópicos y las de carácter natural no biológico. Las observaciones se han realizado utilizando lupas de mano $10 \mathrm{X}$ y $20 \mathrm{X}$ y lupa binocular de hasta 40X. Las modificaciones a la metodología citadas anteriormente, no afectan a la clasificación que el autor propone en cuanto a la clasificación por tamaños y muy ligeramente a la división anatómica. De este modo se consideran animales de pequeño tamaño a los macromamíferos entre $5 \mathrm{~kg}$ y $100 \mathrm{~kg}$ de peso, en este grupo estarían los pequeños bóvidos y cérvidos como la cabra, el rebeco o el corzo; de tamaño medio a los que superan los $100 \mathrm{~kg}$ sin superar los $250 \mathrm{~kg}$ como por ejemplo el jabalí, el ciervo o el reno; de tamaño grande-mediano a los que superan los $250 \mathrm{~kg}$ citados, sin llegar a sobrepasar los $500 \mathrm{~kg}$ como el caballo; los superiores a este peso se consideran como de talla grande hasta los $800 \mathrm{~kg}$ y los que sobrepasan este 
límite, se consideran como muy grandes. Los carnívoros de cualquier tamaño son tratados individualmente. Por lo que respecta a la división anatómica, el esqueleto se ha dividido en cinco partes: craneal; axial en la que además de las vértebras, costillas y esternón se incluyen la escápula y la pelvis; apendicular superior formado por húmero y fémur; apendicular intermedio en el que se ha incluido el radio, la ulna, la tibia y la fíbula y por último apendicular inferior en el que se encuadran los carpos, tarsos, metacarpos, metatarsos y la totalidad de las falanges.

La cuantificación se ha realizado utilizando las nomenclaturas habituales NR (número de restos identificados e indeterminados), siendo este parámetro el utilizado para el cálculo porcentual de las marcas de carácter biológico tanto antrópico como no antrópico, NME (número mínimo de elementos) en cuyo cálculo se han incluido las diáfisis (Marean y Kim 1998) y NMI (número mínimo de individuos, diferenciando la lateralidad, edad y el sexo).

Para los cálculos de estacionalidad y mortalidad del ciervo y del rebeco, hemos utilizado el grado de desgaste de los molares definitivos inferiores y el del último premolar, $\mathrm{dp}_{4}$ de las piezas deciduales (Klein et al. 1981; Klein y Cruz-Uribe 1983; Steele 2002; Pérez-Barbería y Pérez-Fernández 2009).

Los resultados completos de estos trabajos, incluidos los biométricos, serán publicados en el futuro pero dado que el propósito de esta comunicación, se limita al aporte de datos para el análisis del proceso de especialización-diversificación observado en el Paleolítico superior, tan solo utilizaremos los que creemos necesarios para este fin, entre los cuales, los tafonómicos, tienen desde nuestro punto de vista, una especial incidencia.

\section{RESULTADOS}

Antes de exponer con amplitud los resultados arqueozoológicos y tafonómicos, citaremos los datos referidos al estado de preservación de las superficies corticales observadas, de este modo intentamos confirmar la ausencia de removilizaciones posteriores a su deposición. Con respecto a esta cuestión, indicamos que el porcentaje de restos que presentan abrasión: $2,8 \%$, rodamiento: $0,03 \%$ o pulido: $0,3 \%$, es pequeño, más si tenemos en cuenta que en el caso de la abrasión, el más elevado, lo es de tipo alto tan solo en un 0,2 \% (Tab. 2).

\begin{tabular}{|l|r|r|}
\hline \multicolumn{1}{|c|}{ Alteración } & N ${ }^{\circ}$ restos & \% s/total \\
\hline Superficie cortical en mal estado & 1.290 & $12,60 \%$ \\
\hline Concreción calcárea alta & 667 & $6,50 \%$ \\
\hline Alteraciones de tipo gástrico & 422 & $4,10 \%$ \\
\hline Abrasión & 292 & $2,80 \%$ \\
\hline Abrasión alta & 20 & $0,20 \%$ \\
\hline
\end{tabular}

A TABLA 2. Principales alteraciones de la superficie cortical observadas.
Entendemos por tanto, que la muestra no ha sufrido sustancialmente, por procesos ajenos a la propia génesis del yacimiento, y que no ha habido removilizaciones posteriores, al menos en estas zonas.

En los apartados de alteraciones biológicas y no biológicas, destacan por su elevado porcentaje los restos que presentan concreción calcárea $(6,5 \%$ en grado alto) y los que presentan alteraciones de tipo gástrico $(4,1 \%)$; estas dos alteraciones son las responsables del $84,4 \%$ de las superficies corticales en mal estado observadas (Tab. 2). Las alteraciones por concreción de carbonato cálcico, son muy frecuentes en yacimientos de entornos kársticos; por lo que respecta a las producidas por procesos digestivos serán comentadas más adelante con detalle.

Conviene asimismo llamar la atención sobre el alto grado de fragmentación de la muestra, circunstancia que ya fue advertida en los estudios de Soto (1984). Los restos menores de $3 \mathrm{~cm}$ superan el $80 \%$ del total en todos los niveles (Tab. 3), siendo más elevado el porcentaje en los recuperados en las excavaciones efectuadas por Menéndez que en las realizadas por Olávarri.

\begin{tabular}{|l|r|r|r|}
\hline \multicolumn{1}{|c|}{ Tamaño } & Nivel & $N^{\circ}$ rest. & \% s/Niv \\
\hline$>3 \mathrm{~cm}$ & 1 & 240 & $16,38 \%$ \\
\hline$<3 \mathrm{~cm}$ & 1 & 1.225 & $83,62 \%$ \\
\hline$>3 \mathrm{~cm}$ & 2 & 649 & $16,27 \%$ \\
\hline$<3 \mathrm{~cm}$ & 2 & 3.340 & $83,73 \%$ \\
\hline$>3 \mathrm{~cm}$ & 3 & 768 & $15,95 \%$ \\
\hline$<3 \mathrm{~cm}$ & 3 & 4.047 & $84,05 \%$ \\
\hline Totales & 10.269 & \multicolumn{2}{|l}{} \\
\cline { 1 - 3 } & &
\end{tabular}

$\Delta$ TABla 3. Número de restos mayores y menores de $3 \mathrm{~cm}$ de la macrofauna de las Zonas A e Interior de la cueva del Buxu.

\subsection{Taxonomía, anatomía y estacionalidad}

Debido fundamentalmente al alto grado de fragmentación citado, el porcentaje de determinación taxonómica es pequeño: 6,46 \%; incluso utilizando la agrupación por tamaño de los macromamíferos usada, los indeterminados suponen el $68,6 \%$.

Hay un claro predominio de los restos de herbívoros sobre los carnívoros y entre los primeros, los de pequeño tamaño, Rupicapra rupicapra y Capra pyrenaica, siguiéndole en importancia los de Cervus elaphus. La presencia de restos atribuidos a animales de gran tamaño, así como los pertenecientes a Sus scropha en todos los niveles, pueden considerarse como testimoniales. De entre los carnivoros, y aunque el número de restos no es elevado, destacan los pertenecientes a los cánidos: Canis lupus y Vulpes vulpes (Tablas 4 y 5).

Se deduce por los datos expuestos, que los dos taxones predominantes en el yacimiento son el ciervo y el rebeco, 


\begin{tabular}{|c|c|c|c|c|c|c|c|c|c|c|c|c|c|c|c|c|c|c|c|c|c|c|c|c|c|c|c|c|c|c|c|c|c|c|c|}
\hline \multirow{3}{*}{ TOTAL } & \multicolumn{5}{|c|}{ Equus } & \multicolumn{4}{|c|}{ Bos } & \multicolumn{4}{|c|}{ Cervus elaphus } & \multicolumn{4}{|c|}{ Capra pyrenaica } & \multicolumn{5}{|c|}{ Rupicapra rupicapra } & \multicolumn{5}{|c|}{ Sus scropha } & \multicolumn{4}{|c|}{ Canis lupus } & \multicolumn{4}{|c|}{ Vulpes vulpes } \\
\hline & \multirow{2}{*}{ NR } & \multicolumn{2}{|c|}{ MNI } & \multirow{2}{*}{\multicolumn{2}{|c|}{ MNE }} & \multirow{2}{*}{ NR } & \multicolumn{2}{|c|}{ MNI } & \multirow{2}{*}{ MNE } & \multirow{2}{*}{ NR } & \multicolumn{2}{|r|}{ MNI } & & & MNI & & & & & MNI & & & & & MNI & & & & M & NI & & & & MNI & \\
\hline & & \begin{tabular}{|l|}
$1-3$ \\
\end{tabular} & A & & & & $\mid-1$ & \begin{tabular}{l|l}
$A$ & $S$
\end{tabular} & & & I-J & \begin{tabular}{|l|l} 
A & S
\end{tabular} & s & & \begin{tabular}{l|l|} 
I-J & A \\
\end{tabular} & $\mathrm{s}$ & & & \begin{tabular}{|l|}
$1-5$ \\
\end{tabular} & A & $\mathrm{s}$ & & & I-J & \begin{tabular}{l|l}
$A$ & $S$
\end{tabular} & & & & \begin{tabular}{l|l} 
I-J & $A$
\end{tabular} & $\mathrm{As}$ & & & \begin{tabular}{|l|}
$1-3$ \\
\end{tabular} & \begin{tabular}{l|l|}
$A$ & $S$
\end{tabular} & \\
\hline Cuemo/asta & & & & & & & & & & 8 & & 3 & 3 & & & & & 6 & & 2 & & 2 & & & & & & & & & & & & & \\
\hline Cráneo & & & & & & & & & & 4 & & 2 & 2 & 1 & 1 & 1 & 1 & 2 & & 2 & & 2 & & & & & & & & & & 1 & & 1 & 1 \\
\hline Maxilar & & & & & & & & & & 2 & 1 & 1 & & 2 & & & & 8 & & 3 & 1 & 7 & & & & & & & & & & & & & \\
\hline Mandibula & & & & & & & & & & 9 & 2 & 3 & 5 & & & & & 24 & 4 & 4 & 3 & 12 & & & & & & & & & & & & & \\
\hline Dentición & 3 & & 1 & & 3 & 3 & & 1 & 2 & 40 & 6 & \begin{tabular}{|l|}
4 \\
\end{tabular} & $\begin{array}{l}40 \\
40\end{array}$ & 9 & 4 & 4 & & 136 & 6 & 8 & 5 & 163 & 1 & & 1 & & 1 & 3 & & 2 & 3 & 8 & & 3 & $\varepsilon$ \\
\hline Vértebra & & & & & & & & & & 9 & & 3 & 5 & 1 & 1 & 1 & 1 & 1 & & 1 & & 1 & & & & & & & & & & 1 & & 1 & 1 \\
\hline Costilla & & & & & & & & & & & & & & & & & & & & & & & & & & & & & & & & & & & \\
\hline Escápula & & & & & & & & & & & & & & & & & & & & & & & & & & & & & & & & & & & \\
\hline Húmero & & & & & & & & & & 4 & 1 & 1 & 2 & 2 & 2 & 2 & 2 & $\begin{array}{ll}2 & 6 \\
\end{array}$ & 1 & 2 & & 3 & & & & & & & & & & & & & \\
\hline Radio/Ulna & & & & & & & & & & 8 & & 3 & 5 & 2 & 1 & 1 & 2 & $\begin{array}{ll}214 \\
\end{array}$ & & 5 & & 8 & & & & & & & & & & & & & \\
\hline Carpos & & & & & & & & & & 18 & 1 & 3 & 18 & 2 & 1 & 1 & 2 & $\begin{array}{ll}211 \\
11\end{array}$ & & 3 & & 11 & & & & & & & & & & 1 & & 1 & 1 \\
\hline Metacarpo & & & & & & 1 & & 1 & 1 & 20 & 3 & 4 & 8 & 1 & 1 & 1 & 1 & 7 & 1 & 4 & & 5 & & & & & & & & & & 1 & & 1 & 1 \\
\hline Pelvis & & & & & & & & & & 4 & 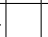 & 2 & 2 & 1 & 1 & 1 & 1 & 3 & & 1 & & 2 & & & & & & & & & & 1 & & 1 & 1 \\
\hline Fémur & & & & & & & & & & 6 & 1 & 3 & 4 & 1 & 1 & 1 & 1 & 1 & & 1 & & 1 & 1 & & 1 & & 1 & & & & & & & & \\
\hline Patela & & & & & & & & & & & & & & 1 & 1 & 1 & 1 & 3 & & 2 & & 3 & & & & & & & & & & & & & \\
\hline Tibia & & & & & & & & & & 8 & & 3 & 3 & 2 & 1 & 1 & 1 & 5 & 1 & 2 & & 3 & & & & & & & & & & 1 & & 1 & 1 \\
\hline Calcáneo & & & & & & & & & & 1 & & 1 & 1 & & & & & 8 & & 4 & & 8 & & & & & & & & & & & & & \\
\hline Astrágalo & & & & & & & & & & 2 & & 1 & 2 & & & & & 3 & & 2 & & 3 & & & & & & & & & & & & & \\
\hline Metatarso & & & & & & & & & & 31 & 1 & 3 & 5 & 1 & 1 & 1 & 1 & 1 & & 1 & & 1 & & & & & & & & & & 1 & & 1 & 1 \\
\hline Tarso & & & & & & & & & & 7 & & 3 & 7 & 1 & 1 & 1 & 1 & $\begin{array}{ll}1 & 6 \\
\end{array}$ & 1 & 2 & & 6 & & & & & & 1 & & 1 & 1 & & & 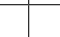 & \\
\hline Falanges & & & & & & & & & & 45 & 1 & 3 & 35 & 17 & 3 & 3 & 10 & 31 & & 4 & & 24 & 2 & & 1 & & 2 & 1 & & 1 & 1 & 1 & & 1 & 1 \\
\hline Sesamoideo & & & & & & & & & & 10 & & 2 & 10 & 3 & 1 & 1 & 3 & \begin{tabular}{|l|l}
3 & 5 \\
\end{tabular} & & 2 & & 5 & & & & & & 1 & & 1 & 1 & & & & \\
\hline Metapodos & & & & & & 1 & 1 & & 1 & 9 & & 3 & 3 & 1 & 1 & 1 & 1 & it & & & & & & & & & & & & & & 3 & & 1 & 2 \\
\hline Hyoides & & & & & & & & & & 1 & & 1 & 1 & & & & & & & & & & & & & & & & & & & & & & \\
\hline $\begin{array}{l}\text { Resumen } \\
\text { MNI }\end{array}$ & 3 & & 1 & & 3 & 5 & 1 & 2 & & 246 & 6 & $4 \mid$ & 1632 & 46 & 4 & 4 & & 282 & 6 & 8 & 5 & 244 & 4 & & 2 & & 4 & 6 & the & 2 & 6 & 19 & & 3 & 18 \\
\hline
\end{tabular}

\ Tabla 4. Datos taxonómicos y anatómicos totales de la macrofauna de las Zonas A e Interior de la cueva del Buxu.

especies sobre cuyos datos nos centraremos de aquí en adelante de manera más intensa.

\subsubsection{Cervus elaphus}

Por lo que se refiere al ciervo, los elementos anatómicos presentes son similares a los ofrecidos por el rebeco y excepto la escápula, se encuentran presentes todos ellos (Tab. 4 y Fig. 7).

Aunque en pequeña cantidad, hay costillas y vértebras en el registro, La presencia simultánea de cabra y rebeco y la elevada fragmentación de la muestra, hace que, excepto en casos excepcionales la diferenciación de las vértebras a nivel taxonómico sea difícil. En el caso de las costillas la dificultad de identificación es aún mayor. Para evitar que por su tamaño (una posible mejor determinación de las costillas de ciervo), incida en los resultados comparativos, las hemos omitido en todos los taxones de la tabla 4.

Los datos comparativos de las partes anatómicas atribuidas al esqueleto craneal, axial o apendicular, figuran agrupados por el tamaño estimado de los macromamíferos, en la figura 3. Con pocas diferencias, los porcentajes obtenidos (utilizando el número de restos) son similares y se observa, un claro predominio de los elementos apendiculares.

No hay una cantidad suficiente de restos dentales de Cervus elaphus, como para efectuar un estudio de mortali- dad similar al que efectuamos más adelante del rebeco, sin embargo, merece la pena un análisis más detallado de estos restos. De las piezas dentales valorables, en el nivel 1 tan sólo hay un $\mathrm{M}_{3}$ inferior (adulto) y un $\mathrm{dp}_{4}$ sin raices (neonato); el nivel 2 presenta 10 piezas, de las cuales, tan solo una pertenece a un adulto, el resto son de individuos infantiles y por último, en el nivel 3, de las 12 piezas dentales, tres pertenecen a adultos y el resto a infantiles. La mayoria de las piezas dentales que hemos identificado como pertenecientes a individuos infantiles o juveniles, tienen las raíces en pro-

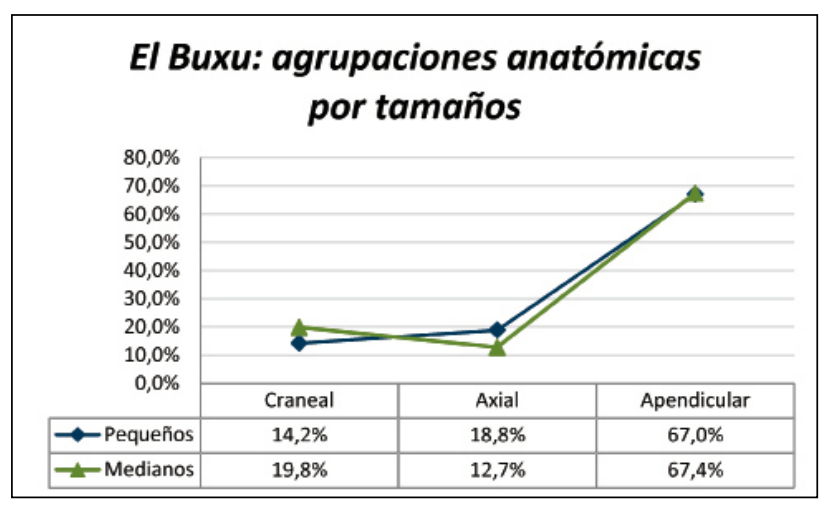

A Figura 3. Porcentaje de restos (NR) en función de la parte del esqueleto a la que han sido asignados y el tamaño de los macromamíferos en la cueva del Buxu. 


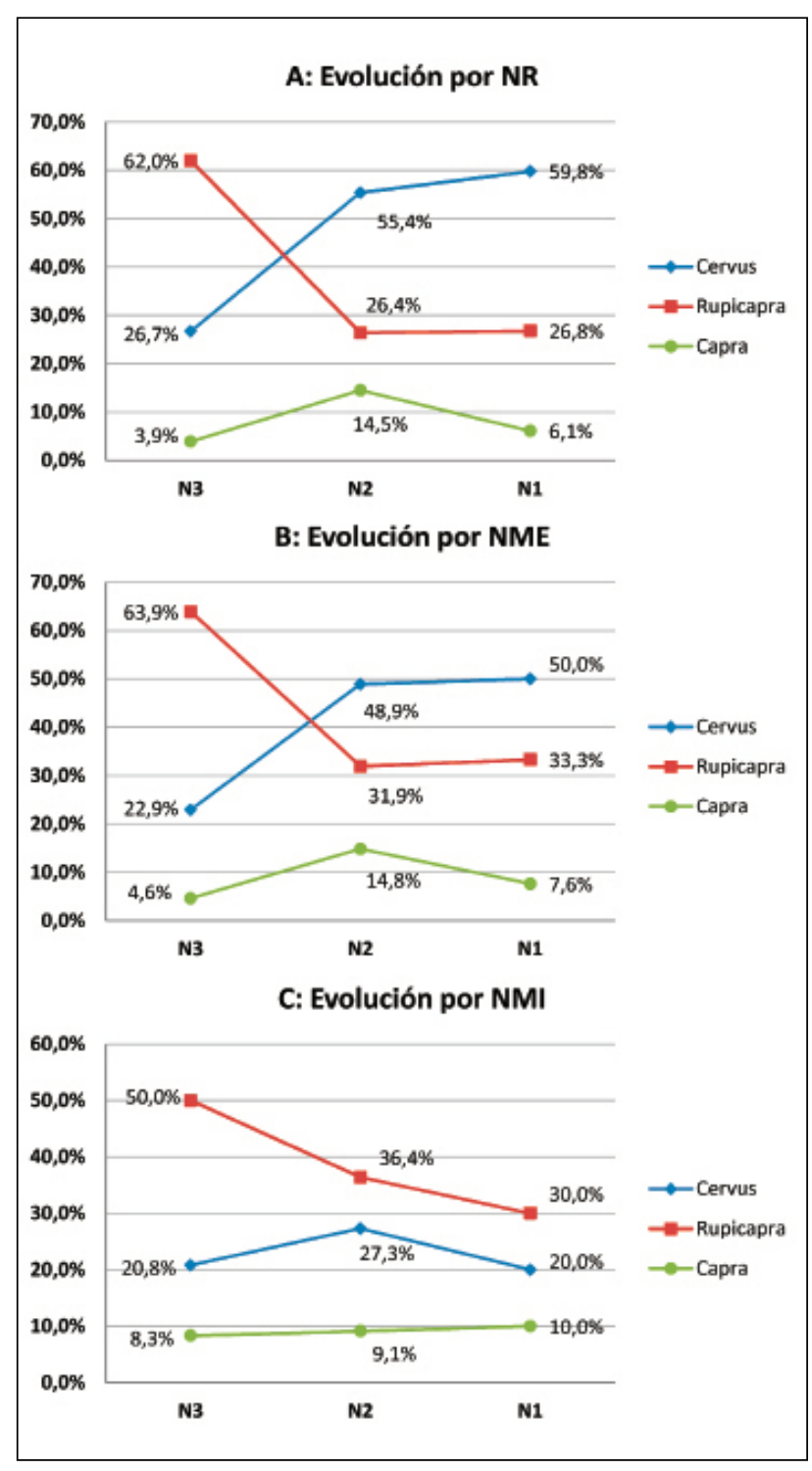

\ Figura 4. Variación porcentual de NR (A), NME (B) y NMI (C) en los niveles 1,2 y 3 de la cueva del Buxu, referidos a Cervus elaphus, Rupicapra rupicapra y Capra pyrenaica.

ceso de formación y lo mismo ocurre, con gran número de fragmentos recuperados (Fig. 5).

Parece por tanto, y aunque carecemos de datos biométricos suficientes para confirmar que los ciervos adultos son hembras, que hay una especial incidencia en la depredación de individuos muy jóvenes y sus madres; la presencia de asta tampoco es determinante, pues de los 8 restos observados, tan solo uno no presenta marcas de haber sido utilizado para la elaboración de varillas o azagayas. A pesar de la salvedad respecto al sexo de los ciervos adultos, deducimos que la estacionalidad para ciervo, parece centrarse en el momento del parto: abril/mayo, y los meses posteriores.

En el cómputo global de los restos, teniendo en cuenta todos los elementos anatómicos y evaluando la edad en

\begin{tabular}{|l|r|r|r|c|r|r|}
\hline \multicolumn{1}{|c|}{ Nivel 1 } & NR & \multicolumn{1}{c|}{$\%$} & NMI & $\%$ & NME & $\%$ \\
\hline Equus & $0,0 \%$ & $0,0 \%$ & $0,0 \%$ & & & \\
\hline Bos & 1 & $1,2 \%$ & 1 & $10,0 \%$ & 1 & $1,5 \%$ \\
\hline Cervus & 49 & $59,8 \%$ & 2 & $20,0 \%$ & 33 & $50,0 \%$ \\
\hline Capra & 5 & $6,1 \%$ & 1 & $10,0 \%$ & 5 & $7,6 \%$ \\
\hline Rupicapra & 22 & $26,8 \%$ & 3 & $30,0 \%$ & 22 & $33,3 \%$ \\
\hline Sus & $0,0 \%$ & $0,0 \%$ & $0,0 \%$ & & & \\
\hline Canis & 1 & $1,2 \%$ & 1 & $10,0 \%$ & 1 & $1,5 \%$ \\
\hline Vulpes & 3 & $3,7 \%$ & 1 & $10,0 \%$ & 3 & $4,5 \%$ \\
\hline Ursus & 1 & $1,2 \%$ & 1 & $10,0 \%$ & 1 & $1,5 \%$ \\
\hline Totales & 82 & $100,0 \%$ & 10 & $100,0 \%$ & 66 & $100,0 \%$ \\
\hline
\end{tabular}

\begin{tabular}{|l|r|r|r|r|r|r|}
\hline Nivel 2 & NR & \multicolumn{1}{c|}{$\%$} & NMI & \% & NME & $\%$ \\
\hline Equus & $0,0 \%$ & $0,0 \%$ & $0,0 \%$ & & & \\
\hline Bos & 3 & $1,6 \%$ & 1 & $9,1 \%$ & 2 & $1,5 \%$ \\
\hline Cervus & 107 & $55,4 \%$ & 3 & $27,3 \%$ & 66 & $48,9 \%$ \\
\hline Capra & 28 & $14,5 \%$ & 1 & $9,1 \%$ & 20 & $14,8 \%$ \\
\hline Rupicapra & 51 & $26,4 \%$ & 4 & $36,4 \%$ & 43 & $31,9 \%$ \\
\hline Sus & 2 & $1,0 \%$ & 1 & $9,1 \%$ & 2 & $1,5 \%$ \\
\hline Canis & $0,0 \%$ & $0,0 \%$ & $0,0 \%$ & & & \\
\hline Vulpes & 2 & $1,0 \%$ & 1 & $9,1 \%$ & 2 & $1,5 \%$ \\
\hline Ursus & $0,0 \%$ & $0,0 \%$ & $0,0 \%$ & & & \\
\hline Totales & 193 & $100,0 \%$ & 11 & $100,0 \%$ & 135 & $100,0 \%$ \\
\hline
\end{tabular}

\begin{tabular}{|l|r|r|r|r|r|r|}
\hline \multicolumn{1}{|c|}{ Nivel 3 } & NR & \multicolumn{1}{c|}{$\%$} & NMI & NME & N \\
\hline Equus & 3 & $0,9 \%$ & 1 & $4,2 \%$ & 3 & $1,1 \%$ \\
\hline Bos & 1 & $0,3 \%$ & 1 & $4,2 \%$ & 1 & $0,4 \%$ \\
\hline Cervus & 90 & $26,7 \%$ & 5 & $20,8 \%$ & 64 & $22,9 \%$ \\
\hline Capra & 13 & $3,9 \%$ & 2 & $8,3 \%$ & 13 & $4,6 \%$ \\
\hline Rupicapra & 209 & $62,0 \%$ & 12 & $50,0 \%$ & 179 & $63,9 \%$ \\
\hline Sus & 2 & $0,6 \%$ & 1 & $4,2 \%$ & 2 & $0,7 \%$ \\
\hline Canis & 5 & $1,5 \%$ & 1 & $4,2 \%$ & 5 & $1,8 \%$ \\
\hline Vulpes & 14 & $4,2 \%$ & 1 & $4,2 \%$ & 13 & $4,6 \%$ \\
\hline Ursus & 0 & $0,0 \%$ & 0 & $0,0 \%$ & 0 & $0,0 \%$ \\
\hline Totales & 337 & $100,0 \%$ & 24 & $100,0 \%$ & 280 & $100,0 \%$ \\
\hline
\end{tabular}

A TABLA 5. Datos de NR, NME y NMI por niveles de la cueva del Buxu utilizados en este trabajo.

función de la superficie cortical, parece haber una cierta tendencia a la disminución del nivel 3 al 1, de restos pertenecientes a infantiles y juveniles.

\subsubsection{Rupicapra rupicapra}

La presencia de restos de rebeco es abundante en todos los niveles aunque se observa una tendencia a disminuir según se avanza temporalmente en los niveles.

Como ya se ha comentado, están presentes casi todos los elementos anatómicos y aunque el mayor número se da en el esqueleto craneal, esto se debe como es habitual al peso estadístico de los restos dentales (Tab. 4 y Fig. 8).

Para este taxón y dado el elevado número de restos dentales completos, si se han podido elaborar patrones de mortalidad por niveles. El que se puede observar en la Fi- 
Figura 5. Mandíbula izquierda de ciervo infantil del Nivel 2 de la Zona Interior de la cueva del Buxu.

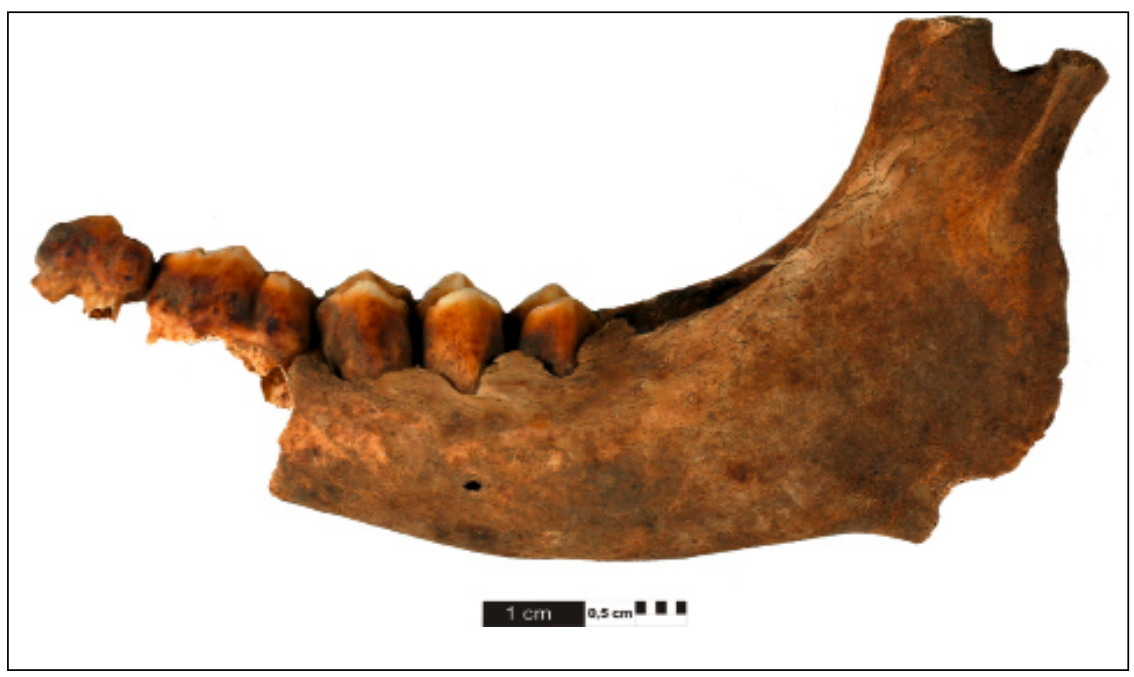

gura 6, incluye la totalidad de los restos y niveles. Se aprecia, que las edades en el momento de la muerte, cubren la práctica totalidad del ciclo vital del rebeco, alejándose en este caso, del patrón establecido para el ciervo, en el que la depredación se centra, aunque no de modo exclusivo, en individuos jóvenes.

El desglose por niveles, nos indica que los números 1 y 3 , son muy homogéneos, estando ausentes los individuos infantiles y juveniles en el nivel 2. La amplitud de los datos ofrecidos por el método utilizado, no permite efectuar estudios de estacionalidad del yacimiento, al menos, utilizando el desgaste dental del rebeco como referencia. Si se puede observar, una cohorte de edades muy amplia, con predominio de los individuos adultos, y lo que podríamos determinar como seniles.

\subsection{Marcas antrópicas y producidas por carnívoros}

Así como el número de restos determinados taxonómicamente es escaso, el número de estos en los que se aprecian marcas de origen antrópico, o producidas por carnívoros, es suficientemente alto como para ser tratado al menos someramente.

Los tipos de marca antrópica más comunes son las de corte y de descarnado, siendo menor el número de restos en los que se puede apreciar marcas de golpeo. Por lo que respecta a las producidas por carnívoros, las más frecuentes, son los denominados pits y los surcos, aunque también se ha podido determinar en algún caso, muescas vinculadas a las anteriores. Además de las marcas producidas por diente, en la Tabla 6, se puede ver por niveles, un desglose de las que hemos encontrado de tipo gástrico y que también creemos han sido producidas por carnivoros.

Si efectuamos una comparación de las figuras 7 y 8 , se puede observar que si en el caso del ciervo, el dominio de las antrópicas es claro, para el rebeco se invierte la tenden- cia y dominan las producidas por carnívoros. La utilización en la figura del sarrio de los datos del nivel 3 exclusivamente, se debe a que es el más significativo ya que, entre los restos del nivel 1, contando con nueve elementos anatómicos, no hay ninguno que presente marcas ni antrópicas ni de carnívoros; en el nivel 2, con mayor abundancia de elementos: 25 , tan solo uno de ellos presenta una marca de corte y dos más de dientes. Es el nivel 3, el más antiguo, en el que hay mayor número de restos con presencia de este tipo de marcas.

En el caso del ciervo, las marcas de carácter antrópico, aparecen en todos los niveles, creciendo en porcentaje sobre los restos desde un $8,6 \%$ en el nivel 3 a un 13,3\% en el nivel 1 (para el cálculo de estos porcentajes, no se han incluido las piezas dentales).

\section{DISCUSIÓN}

La cuantificación en arqueozoología, es una de las cuestiones que más debate provoca (Lyman 2008) y, llegar a una unificación de criterios, parece una tarea ardua y complicada. Esto es así pues cada yacimiento, incluso cada nivel, tiene una serie de particularidades que hacen que para su mejor explicación y comprensión, se adopten unos u otros criterios.

La mayor o menor fragmentación del registro, tiende a que algunos taxones, se vean favorecidos o desfavorecidos porcentualmente en el NR y en el NMI. El NME exige además, un trabajo adicional de identificación anatómica y de recopilación de los datos obtenidos. Hemos optado por ofrecer los tres indicados por ser de los más utilizados en arqueozoología; los resultados se pueden ver en la tabla 5 y la figura 4.

Los datos referidos al NR y NME, muestran claramente que mientras la presencia de ciervo aumenta, simultáneamente va descendiendo la presencia de rebeco con unos por- 


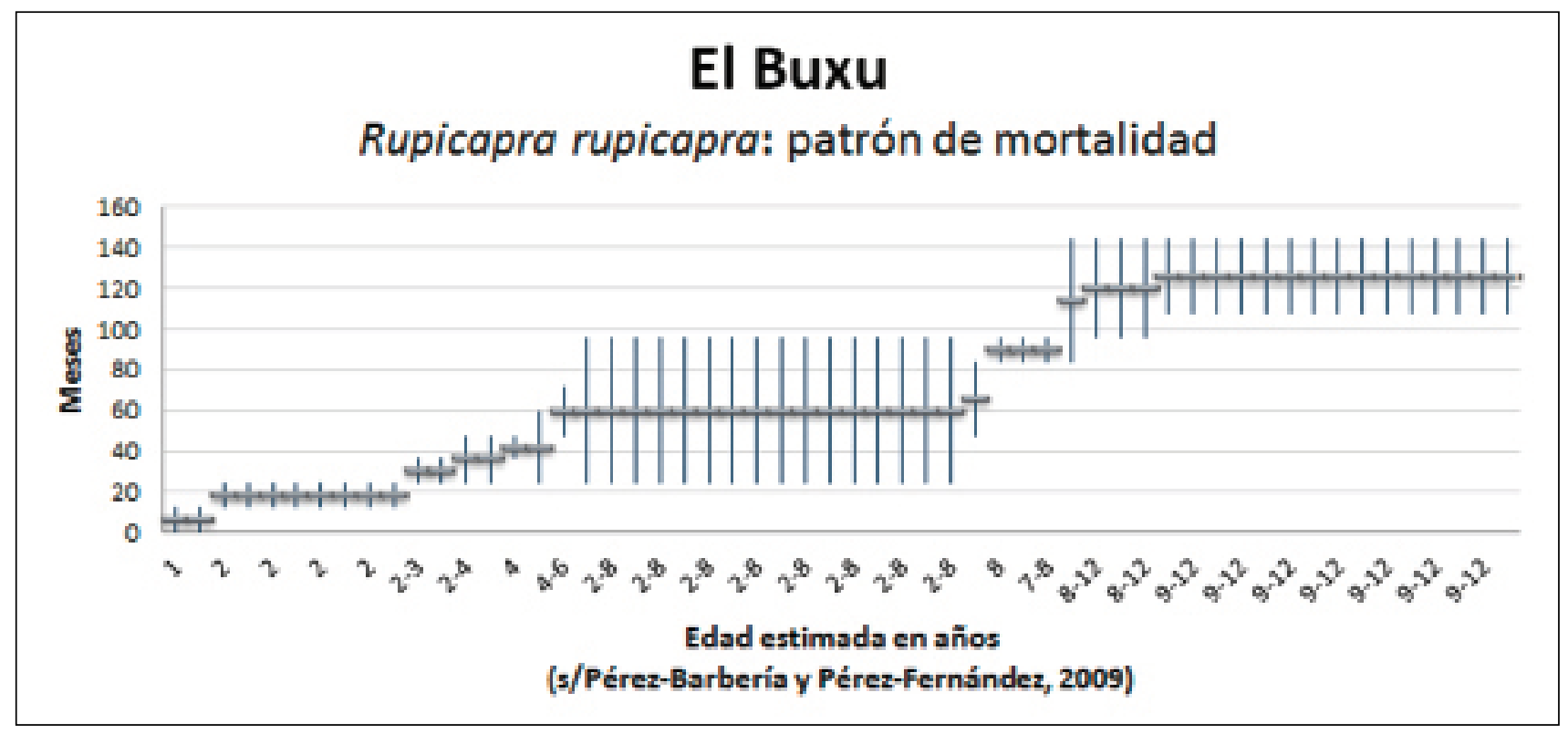

A Figura 6. Patrón de mortalidad de rebeco en la cueva del Buxu (datos globales de las Zonas A e Interior)

centajes de cabra bastante similares, aunque con un cierto repunte en el nivel 2.

El peso porcentual del resto de taxones: carnivoros, Equus, Bos, etc., oscila entre un $5 \%$ y un $10 \%$ aproximadamente. Esta circunstancia se ve sustancialmente alterada, si el dato que utilizamos es el NMI pues, pasa de un $22 \%$ en el nivel 3 a un $40 \%$ en el nivel 1. La importancia de las especies menos representadas, crece de manera inversa al número de restos de cada nivel. Se da la paradoja que en el nivel 1, el lobo con un solo resto aporta un individuo y el ciervo, el taxón con mejor representatividad del nivel en los otros parámetros, con 54 restos de los cuales tan sólo 4 son dentales, solo aporta dos, dato menor incluso que el del sarrio, pues 22 restos, trece de ellos dentales, nos ofrecen un NMI de 3 ; en nuestra opinión la escasa muestra recuperada de este nivel, sobrevalora los resultados obtenidos mediante el NMI, dando una importancia a taxones que el resto de datos no sustenta.

Aun así, lo evidente es que hay un descenso continuado de la presencia de rebeco y que como ya se ha comentado, con la excepción del dato de NMI, la presencia de ciervo se va acrecentando.

Como comentábamos anteriormente, si para el ciervo hay una estacionalidad clara centrada en la caza en el mo-

\begin{tabular}{|l|r|r|l|}
\hline \multicolumn{1}{|c|}{ Nivel } & $\mathrm{N}^{\circ}$ restos & \multicolumn{1}{c|}{ Total } & \multicolumn{1}{l|}{$\%$} \\
\hline 1 & 1.465 & 32 & $2,2 \%$ \\
\hline 2 & 3.989 & 55 & $1,4 \%$ \\
\hline 3 & 4.815 & 335 & $7,0 \%$ \\
\hline Totales & 10.269 & 422 & $4,1 \%$ \\
\hline
\end{tabular}

A TABLA 6. Detalle de marcas de tipo digestivo por niveles en la cueva del Buxu. mento del parto, la amplitud de los datos obtenidos sobre la edad en el momento de la muerte del rebeco, nos impide marcar pautas claras de estacionalidad para este importante taxón del yacimiento. Sin embargo, si nos sirven para comprobar que las cohortes de edades, se diferencian sustancialmente de las señaladas para el ciervo pues abarcan todas las edades posibles de los rebaños, marcando un perfil de mortalidad atricional, perfil similar al que produce la caza de ciervos efectuada por lobos (Steele 2002); esta circunstancia no determina que el origen de los restos, pueda ser atribuido a este carnívoro. Este perfil de mortalidad, la situación del yacimiento y la propia etología del rebeco, si nos pueden marcar algunos datos estacionales de gran interés. El comportamiento migratorio impulsa al rebeco al final de la primavera hacia los pastos altos de montaña que se van liberando de nieve; es este el momento en el que suelen nacer las crías. El rebeco, vuelve a entornos más resguardados, como podría ser el valle en que se encuentra El Buxu, a finales del otoño, cuando se avecinan los rigores invernales. La práctica ausencia de individuos infantiles y la abundancia de los considerados como adultos y seniles, nos indica por un lado, que no se cazaron infantiles y que además, esta caza se efectuó en las cercanías del yacimiento o sea, entre el final del otoño y el comienzo de la primavera.

La discusión sobre el agente acumulador de los restos es, junto con la cuantificación, objeto continuo de controversia. En el caso del Buxu -fuera claramente del debate caza / carroñeo-, la intervención antrópica en la formación de los tres niveles es indudable, parece incluso que mayor, si en lo que fijamos nuestra atención es en los restos de ciervo. Sin embargo, también está presente la acción de los carnivoros fundamentalmente sobre el rebeco, y esto, debe ser valorado. 


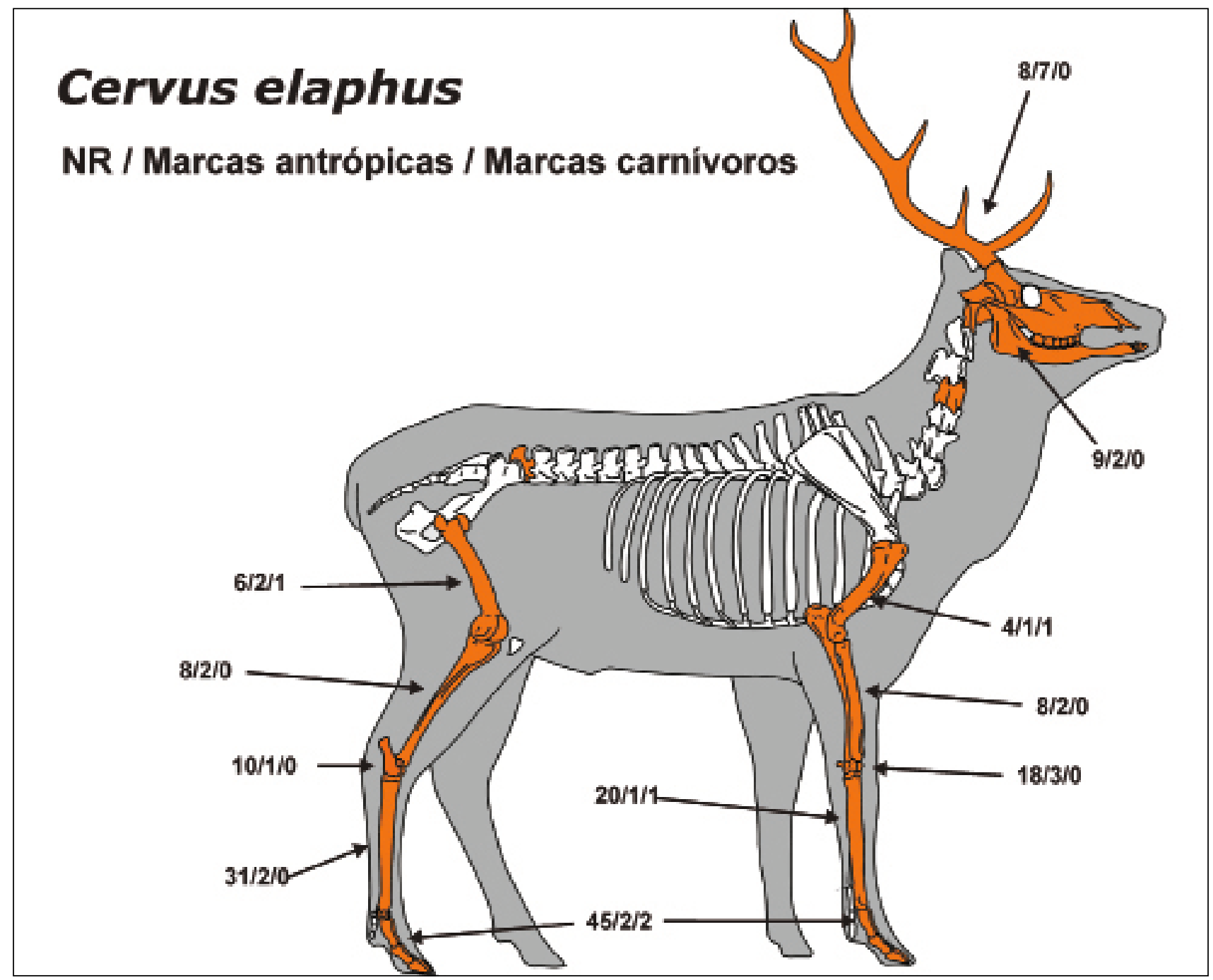

\ Figura 7. Elementos anatómicos de ciervo representados (sombreados) y número de marcas antrópicas y marcas producidas por carnívoros.

De los carnivoros, los que mayores porcentajes de restos ofrecen en el registro de la cueva del Buxu, son el zorro y el lobo. Sus restos, se encuentran en todos los niveles, pero es el nivel 3 , el que los presenta en mayor número, con un claro predominio del zorro.

Hay abundante bibliografía sobre acumulaciones óseas provocadas por hienas; también, aunque en menor cantidad, se han publicado sobre las provocadas por zorros (Mondini 1995; Krajcarz y Krajcarz 2012). Sobre el lobo como agente generador de concentraciones óseas, la documentación es hasta ahora prácticamente inexistente, de hecho, no se considera al lobo como agente acumulador.

En el caso del Buxu, sería factible que tanto el zorro como el lobo, hubieran procedido al carroñeo de los restos aportados por el hombre. Esta opción, estaria en concordancia con lo observado por Pérez-Barbería y Pérez Fernández (2010) sobre la ausencia de carroñeo en los restos craneales, por parte del zorro, pues existe un gran número de restos de esta parte del esqueleto, atribuidos al rebeco en El Buxu. Sin embargo, si consideramos como razonable esta explicación, al analizar los restos con alteraciones de tipo gástrico, esta opción no se sustenta totalmente pues, aunque tanto el zorro como otros carnivoros, incluidos los félidos, generan restos con este tipo de alteración, hemos constatado que en algunos casos su tamaño se acerca a los $3 \mathrm{~cm}$ (Fig. 9). En efecto, algunos de los pequeños fragmentos con alteración de tipo gástrico, podrian haber sido generados por zorros pero, el tamaño de los arriba citados, hace que el tránsito por su aparato digestivo, sea imposible.

El estudio de las alteraciones de tipo gástrico ha crecido en importancia en los últimos años y se han determinado patrones para intentar distinguir las producidas por lobos (Esteban-Nadal, et al. 2010) o por aves como el quebrantahuesos (Marin-Arroyo et al. 2010; Marín-Arroyo y Margalida 2012). La ubicación de la cueva del Buxu, no parece la más idónea para poder atribuir al quebrantahuesos la acumulación de restos de hueso digeridos, pues sus preferencias para nidificar se centran en parajes muy abruptos y escarpados, además, el mayor porcentaje de los restos detectados con 


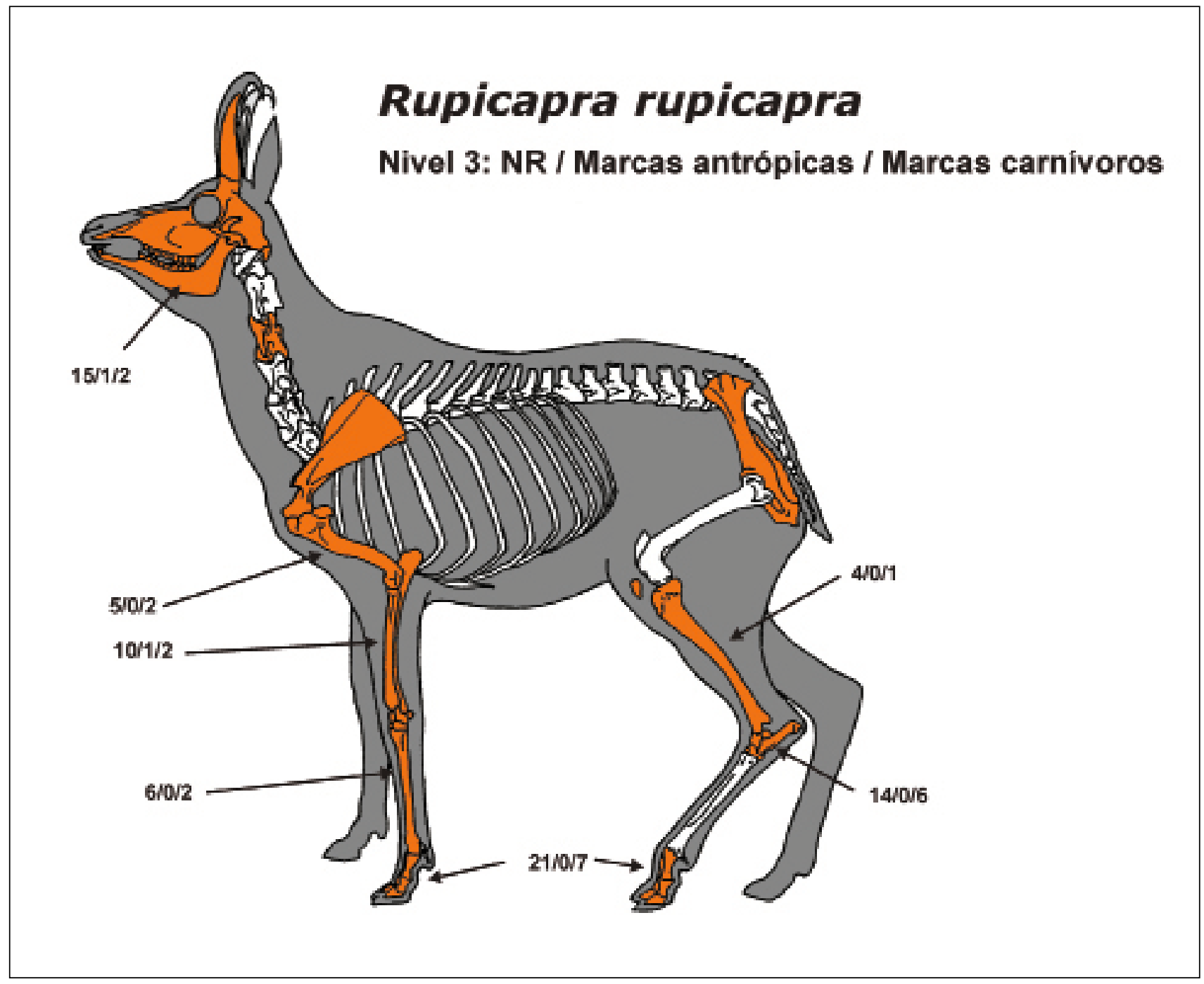

\ Figura 8. Elementos anatómicos de rebeco representados (sombreados) y número de marcas antrópicas y marcas producidas por carnívoros en el Nivel 3.

este tipo de alteración, proviene de la zona interior, muy alejada de la zona actual de acceso.

En el caso de los restos digeridos por lobos, los estudiados por Esteban-Nadal et al. (2010), provienen de excrementos que estos animales utilizan como marcadores de territorio, de zonas de paso o de acceso a zonas de cría. Este podría ser el origen de alguno de los encontrados en El Buxu, aunque en los de mayor tamaño, habría que considerar también, la posibilidad de que provengan de regurgitaciones, para alimentar a las camadas.

Además del hombre, en la actualidad, los únicos animales que depredan rebecos adultos son el lince y el lobo, y la efectividad de su ataque, es mayor en zonas de buena cobertura vegetal, como podría ser el enclave de la cueva del Buxu y sus aledaños, que en aquellas otras de montaña abierta (Pérez-Barbería y Pérez-Fernández 2010). Es posible que el lobo, haya sido, junto con el hombre, uno de los agentes acumuladores de restos óseos en El Buxu, pero esto, supondría un comportamiento totalmente diferente al ob- servado hoy en día. Esta cuestión no debe ser descartada en su totalidad, pues es conocida la versatilidad y capacidad de adaptación del lobo a todos los entornos, también a la presión antrópica.

\section{CONCLUSIONES}

Como indicábamos en el preámbulo los datos son preliminares, no obstante, nos permiten obtener algunos datos de gran interés. En nuestra opinión, en la cueva del Buxu, se presentan simultáneamente dos fenómenos interrelacionados. Por un lado se asiste a una especialización centrada en la caza de cervatos, aunque sin despreciar a las ciervas; tampoco al resto de los taxones presentes en el entorno. Entendemos que el responsable de esta caza y del aporte de los restos al yacimiento sería el hombre, así parecen indicarlo las marcas observadas. Temporalmente, se efectuaría en los momentos de parto y posteriores y por tanto, con una pauta 
Figura 9. Izquierda: epífisis distal de metápodo y falange con alteración de tipo digestivo de la cueva del Buxu. Derecha: falange y sesamoideos recogidos de excrementos de lobo (tomado de Esteban-Nadal, et al. 2010).

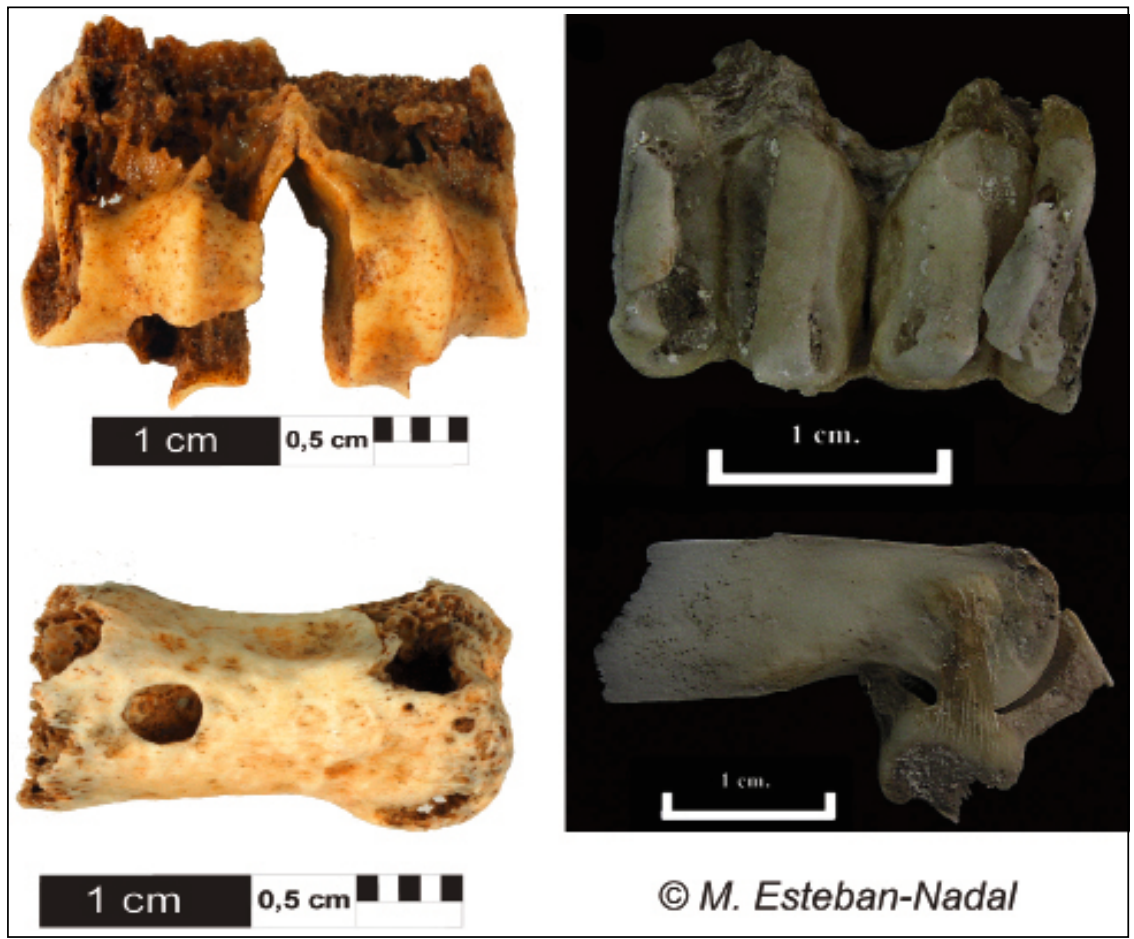

de ocupación estacional antrópica de la cueva, muy determinada. Esta especialización parece que se acentúa aunque levemente con el paso del tiempo, y va paralela a una menor importancia del rebeco en el registro.

Sin dudar que una parte de los restos de rebeco puedan tener un origen antrópico, creemos que los carnívoros también influyeron en la formación del registro, la abundancia de las marcas de todo tipo dejadas por estos en los restos, parece confirmarlo. En el caso del rebeco, las aportaciones se efectuarían desde el final del otoño hasta la primavera, coincidiendo con la presencia de las manadas de rebecos en el entorno. Por otro lado, se observa que la presencia de carnivoros en el registro decae y que las marcas de tipo gástrico se rarifican. Estas circunstancias, nos podrian estar indicando que se produce un abandono paulatino de ese hábitat por parte de los carnívoros. Este abandono podría haber sido provocado, por un uso más intensivo del mismo por los humanos.

No podemos determinar, al menos de momento, el carnívoro o carnívoros a los que creemos responsables de parte de de esta acumulación, sin duda cuando efectuemos la evaluación completa de los resultados, se podrá evaluar con una mayor claridad. El análisis detallado de los datos recogidos, no solamente de los restos determinados (como aquí exponemos), y la valoración entre otras cuestiones del estado de los huesos en el momento de su fracturación, de los ángulos de fractura observados, de la distribución anatómica de las marcas, de si existen superposiciones, etc., nos permitirá acercarnos al grado de incidencia y el taxón o taxones que intervienen. La presencia mayoritaria de cánidos, podría ser una opción pero no hay que descartar cualquier otra. Lo que si parece claro es que utilizando los datos aportados por la tafonomía se pueden matizar las evaluaciones efectuadas; si como los primeros datos parecen indicar, el aporte antrópico no sería el único agente acumulador de restos, El Buxu podría pasar a ser un yacimiento claramente especializado en la caza de ciervos infantiles y sus madres, en el que el rebeco perdería parte de la importancia dada hasta el momento.

\section{AGRADECIMIENTOS}

Queremos mostrar nuestro agradecimiento al Dr. Yravedra por sus siempre acertados comentarios; también al Museo Arqueológico de Asturias en Oviedo, por las múltiples atenciones y facilidades recibidas durante el periodo que permanecimos en él, para el estudio de la muestra. • 


\section{BIBLIOGRAFÍA}

Altuna, J. 1990: La Cueva de Amalda (Zestoa, País Vasco): Ocupaciones paleolíticas y post paleolíticas. Sociedad de Estudios Vascos, San Sebastián.

- 1995: "Faunas de mamíferos y cambios ambientales durante el tardiglaciar". En A. Moure (ed.): El final del Paleolítico Cantábrico. Servicio de Publicaciones de la Universidad de Cantabria. Santander: 77-118.

AltunA, J. y MarieZKurRenA, K. 2010: "Tafocenosis en yacimientos del PaísVasco con predominio de grandes carnivoros. Consideraciones sobre el yacimiento de Amalda". En E. Baquedano y J. Rosell (eds.): Actas de la $1^{a}$ Reunión de científicos sobre cubiles de hiena (y otros grandes carnívoros) en los yacimientos arqueológicos de la Península Ibérica. Zona Arqueológica 13: 215-228.

BREUIL, H. 1952: Quatre cents siècles d'art parietal. Les cavernes ornées de l'âge du Renne. Presses de la Sapho, París.

Corchón Rodríguez, M. S. 1999: "Solutrense y Magdaleniense del Oeste de la Cornisa Cantábrica: dataciones 14C (calibradas) y marco cronológico". Zephyrvs LII: 3-32

Esteban Nadal, M., CÁceres, I. y Fosse, F. 2010: "Characterization of a current coprogenic sample originated by Canis lupus as a tool for identifying a taphonomic agent". Journal of Archaeological Science 37 (12): 2959-2970.

KLEIN, R. G. y CRUZ-URIBE, K. 1983: "The computation of ungulate age (mortality) profiles from dental crown heights". Paleobiology 9 (1): 70-78.

Klein, R. G., Wolf, C., Freeman, L. G. y Allwarden, K. 1981: "The use of dental crown heignts for constructin age profiles of Red deer and similar species in archaeological samples". Journal of Archaelogical Science 8: 1-31.

Krajcarz, M. y Krajcarz, M. T. 2012: "The Red Fox (Vulpes vulpes) as an accumulator of bones in cave-like environments". International Journal of Osteo-archaeology, http://dx.doi.org/10.1002/oa.2233

LYMAN, R.L. 2008: Quantitative Paleozoology. Cambridge University Press, New York.

MAREAN, C. W., KIM, S. Y. 1998: "Mousterian Large-Mammal Remains from Kobeh Cave. Behavioral Implications for Neanderthals and Early Modern Humans". Current Anthropology 39, Suppment June 1998: 79-113.

Marín-Arroyo, A. B., Fosse, P. y Vigne, J. D. 2009: "Probable evidences of bone accumulation by Pleistocene bearded vulture at the archaeological site of El Mirón Cave (Spain)". Journal of Archaeological Science, 36: 284-296.

Marín-Arroyo, A. B. y Margalida, A. 2012: "Distinguishing bearded vulture activities within archaeological contexts: Identificación guidelines". International Journal of Osteoarchaeology 22: 563-576.

Mateos Cachorro, A. 1999: "Alimentación y consumo no cárnico en el Solutrense cantábrico: mandibulas y falanges fracturadas intencionalmente en el Nivel 9 de la Cueva de las Caldas (Priorio, Oviedo)". Zephyrvs LII: 33-52.

MenÉnDEZ, M. 1984: "La cueva del Buxu. Estudio del yacimiento arqueológico y de sus manifestaciones artísticas". Boletín del Real Instituto de Estudios Asturianos, Año 38 n 111:143-186.
- 1992: "Excavaciones arqueológicas en la Cueva del Buxu (Cardes. Cangas de Onís)". Excavaciones arqueológicas en Asturias 198790. Servicio de Publicaciones del Principado de Asturias. Oviedo: 69-74.

- 1999: "La Cueva del Buxu. Cangas de Onís. Campaña de 1998 y resumen de los trabajos anteriores". Excavaciones arqueológicas en Asturias 1995-1998. Consejeria de Cultura del Principado de Asturias. Oviedo: 69-74.

MondinI, M. 1995: "Artiodactyl prey transport by foxes in Puna rock shelters". Current Anthropology 36: 520-524.

Pérez-Barbería, J. F. y Pérez-Fernández, E. 2009: "Identificación, biología y ecología del rebeco cantábrico" En J. F. Pérez-Barbería y $B$. Palacios (eds.) El Rebeco Cantábrico (Rupicapra pyrenaica parva). Conservación y Gestión de sus poblaciones. Organismo Autónomo Parques Nacionales. Ministerio de Medio Ambiente y Medio Rural y Marino. Madrid: 26-69.

QueSADA LóPEZ, J. M. 1995: "Las estrategias de caza durante el Paleolítico superior cantábrico. El caso del oriente asturiano". Complutum 6: 79-103.

- 1997: "La caza en Solutrense Cantábrico: Una nueva perspectiva". Zephyrvs L: 3-36.

Soто, E. 1984: "Restos faunísticos de la Cueva del Buxu, Oviedo". Boletín del Real Instituto de Estudios Asturianos 112: 803-810.

STEELE, T. E. 2002: Red deer: Their ecology and how they were hunted by Late Pleistocene hominids in Western Europe. Tesis doctoral. Stanford University, Stanford, California.

StRAUS, L. G. 1983: El Solutrense vasco-cantábrico. Una nueva perspectiva. Ministerio de Cultura. Centro de Investigación y Museo de Altamira, Monografias 10, Madrid.

- 1986: "The La Riera fauna in regional and temporal perspective". En L. G. Straus G. A. Clark (eds): La Riera Cave. Stone Age huntergatherer adaptations in Northern Spain: 315-321.

YRAVEDRA, J. 2002: "Especialización o Diversificación. Una nueva propuesta para el Solutrense y el Magdaleniense Cantábrico". Munibe 54: 3-20.

- 2004: "Taphonomie d'un gisement solutréen: le niveau IV d'Amalda (Guipzcoa, Espagne)". Préhistoire Anthropologie méditerranéennes 13: 29-41.

- 2006: Tafonomía aplicada a Zooarqueología. UNED, Madrid.

- 2007: "Nuevas contribuciones en el comportamiento cinegético de la Cueva de Amalda". Munibe (Antropologia Arkeologia) 58: 43-88.

- 2010a: "Tafonomía en la Cueva de Amalda: La intervención de carnivoros", en Baquedano, En E. Baquedano y J. Rosell (eds.): Actas de la $1^{a}$ Reunión de científicos sobre cubiles de hiena (y otros grandes carnívoros) en los yacimientos arqueológicos de la Península lbérica. Zona Arqueológica 13: 175-184.

- 2010b: "Zooarqueología y tafonomía del yacimiento de Hornos de la Peña (San Felices de Buelna, Cantabria)". Complutum 21 (1): 69-86.

Yravedra, J. y Gómez-Castanedo, A. 2010: "Tafonomía en Cueva Morín. Resultados preliminares de un estudio necesario". Zephyrvs LXVII: 69-90.

Yravedra, J., Muñoz, E. y Gómez-Castanedo, A. 2010: "Estrategias de subsistencia en el yacimiento del Ruso (Igollo, Camargo, Cantabria, España)". Espacio Tiempo y Forma 3: 39-58. 